\title{
Air2Liquid Method for Selective, Sensitive Detection of Gas- Phase Organophosphates
}

Michael C. Brothers ${ }^{a, b}$, Sungbong Kimc,d, Doug Adkins ${ }^{\mathrm{e}}$, Pat Lewis ${ }^{\mathrm{e}}$, Joshua E. Smith ${ }^{\mathrm{f}}$, Diana

Ostojich $^{\mathrm{g}}$, Steve S. Kimª, John A. Rogers ${ }^{\mathrm{g}-1}$ and H. Mitchell Rubenstein*a

a. 711th Human Performance Wing, Air Force Research Laboratory, Wright-Patterson AFB, OH 45433, United States

b. UES Inc., Dayton OH, 45432

c. Department of Materials Science and Engineering, University of Illinois at Urbana-Champaign, Urbana, IL, 61801 USA

d. Frederick Seitz Materials Research Laboratory, University of Illinois at Urbana-Champaign, Urbana, IL, 61801 USA

e. Defiant Technologies, Albuquerque, NM 87109, USA

f. Department of Chemistry, Alvernia University, Reading, PA 19607, USA.

g. Department of Materials Science and Engineering, Northwestern University, Evanston, IL 60208, USA

h. Simpson Querrey Institute, Northwestern University, Chicago, IL 60611, USA.

i. $\quad$ Center for Bio-Integrated Electronics, Northwestern University, Evanston, IL 60208, USA.

j. Department of Biomedical Engineering, Northwestern University, Evanston, IL 60208, USA.

k. Department of Chemistry, Northwestern University, Evanston, IL 60208, USA.

1. Department of Neurological Surgery, Feinberg School of Medicine, Northwestern University, Chicago, IL 60611, USA. 
SI Figure 1: Immobilization capture is impacted by flow rate through the microreactor functionalized with APTES followed by glutaraldehyde, with $\sim 50 \%$ capture efficiency observed at $30 \mu \mathrm{L} / \mathrm{min}(\mathrm{A})$ as determined by the Bradford assay using bovine serum albumin as a standard. 2 Hours of functionalization at this rate resulted in an observed fluorescence intensity of $75 \%$ max output for the miniaturized detector $(B)$ when the reaction solution contained $100 \mu \mathrm{M}$ of acetylcholine and the fluorescent reporter Amplex $\operatorname{Red}(5 \mu \mathrm{L} / \mathrm{mL}$ of buffer).
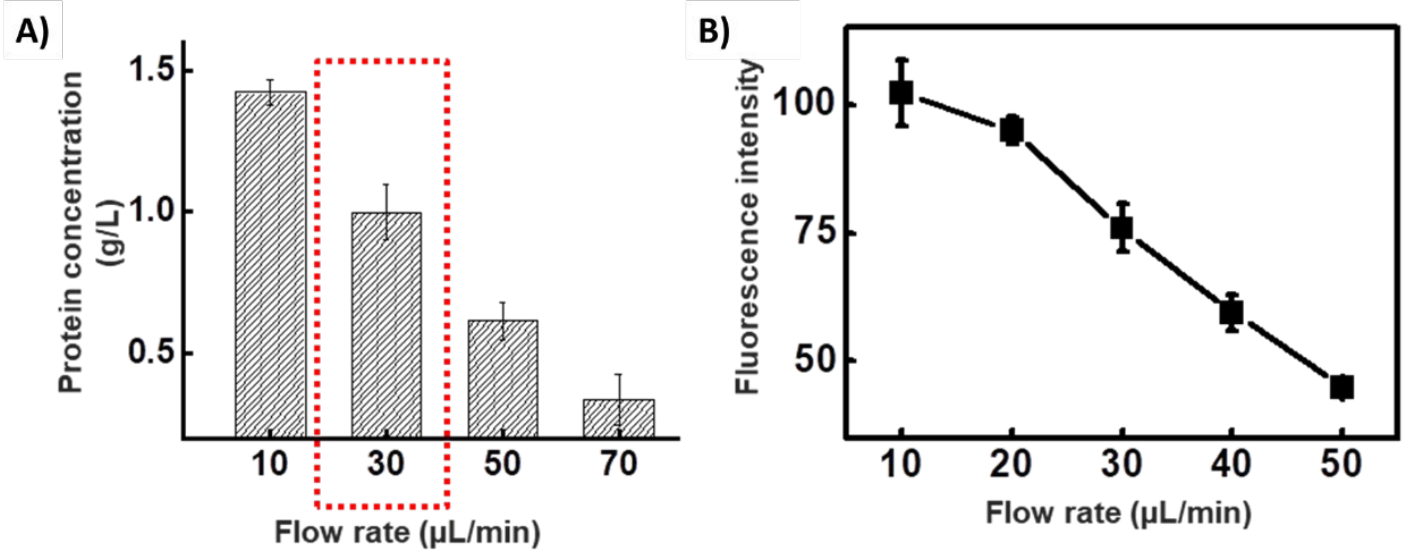
SI Figure 2: Schematic of detector (A) demonstrates how the combination of a green LED, excitation filter, emission filter, and photodetector are combined with a flowthrough aluminum or polymethyl methacrylate (PMMA) cuvette $(B)$ to measure microamp current from fluorescence excitation and emission, that after placement through a high-pass filter can detect a range of fluorescent outputs as current (C). The entire detector was wrapped in black PDMS to minimize fluorescent signal loss.
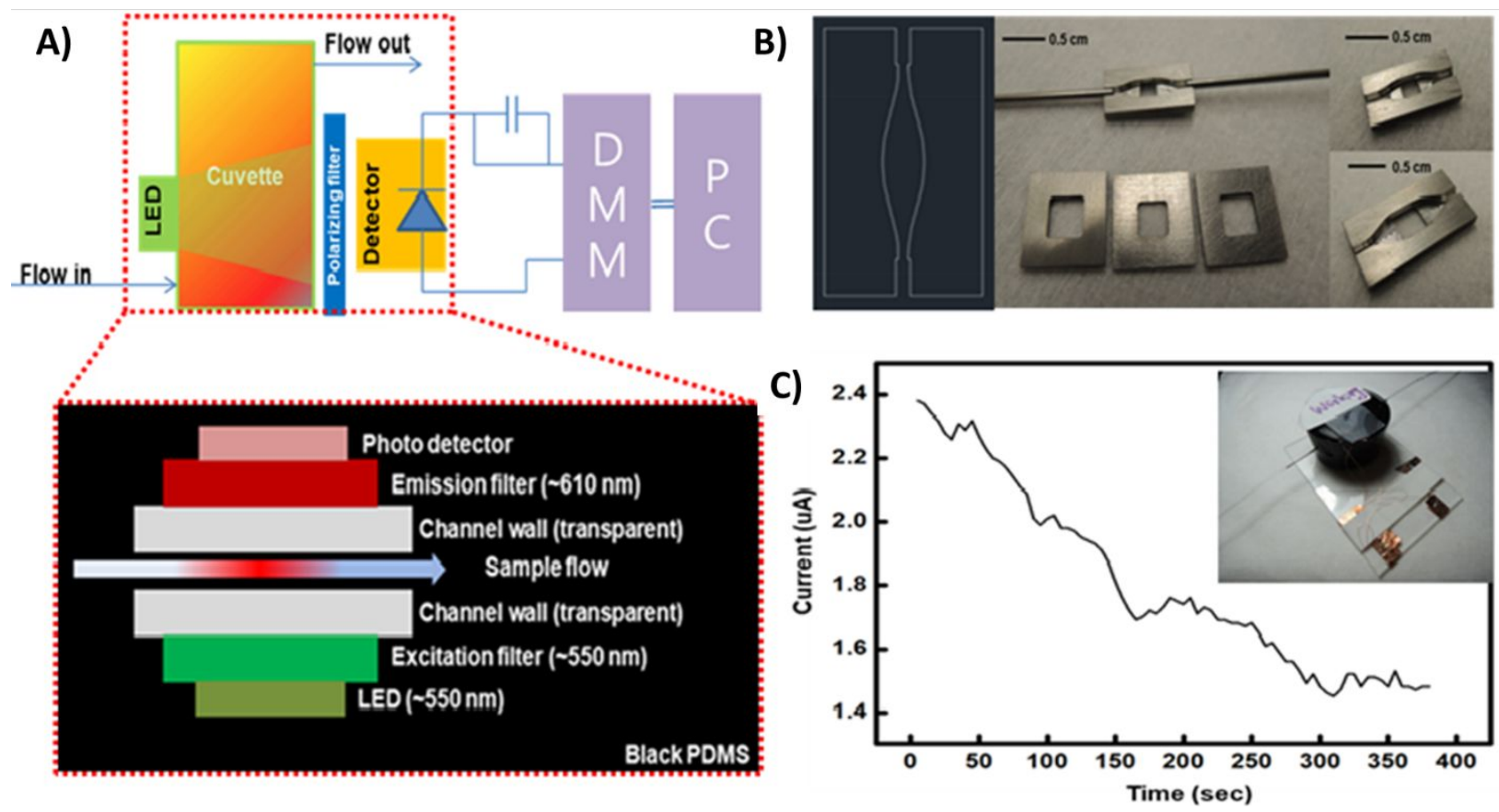
SI Table 1: Partition coefficient (octanol/water) of representative organophosphates demonstrates the increased solubility in organic solvents of the most common organophosphates.

\begin{tabular}{|l|r|}
\hline Compound Name & LogP \\
\hline Azamethiphos & 1 \\
\hline Azinphos-methyl & 2.8 \\
\hline Chlorpyrifos & 5.3 \\
\hline Diazinon & 3.81 \\
\hline Dichlorvos & 1.4 \\
\hline Fenitrothion & 3.3 \\
\hline Malathion & 2.4 \\
\hline Methyl Parathion & 2.9 \\
\hline Parathion & 3.8 \\
\hline Phosmet & 2.8 \\
\hline Terbufos & 4.5 \\
\hline Tetrachlorvinphos & 3.5 \\
\hline Tributyl phosphate & 2.9 \\
\hline Tricresyl phosphate & 5.1 \\
\hline Triphenyl phosphate & 4.6 \\
\hline
\end{tabular}


SI Table 2: Concentration of Tributyl phosphate in $1 \mathrm{~mL}$ hexane aliquots used to rinse the $\mu$-PC tube in the sampler after 5,10 , and 25 minutes of collection from the air residing over a $50 \mathrm{~mL}$ beaker containing $10 \mathrm{~mL}$ of TBP, as determined using a nitrogen phosphorous detector. Air sampling occurred at a rate of $60 \mathrm{~mL} / \mathrm{min}$ for 5,10 , or 25 minutes.

\begin{tabular}{|l|l|l|}
\hline & Peak Area & Conc (ng/ $\mathbf{\mu L})$ \\
\hline $\mathbf{5}$ min collect & & \\
\hline Rinse 1 & 13 & 3.2 \\
\hline Rinse 2 & ND & ND \\
\hline Rinse 3 & ND & ND \\
\hline $\mathbf{1 0}$ min collect & & \\
\hline Rinse 1 & 35 & 8.6 \\
\hline Rinse 2 & 7.8 & 1.9 \\
\hline Rinse 3 & ND & ND \\
\hline $\mathbf{2 5}$ min collect & & \\
\hline Rinse 1 & 53 & 13 \\
\hline Rinse 2 & 14 & 3.4 \\
\hline Rinse 3 & ND & ND \\
\hline inlet tube rinse & 161 & 39.6 \\
\hline 10min & 32 & 7.9 \\
\hline
\end{tabular}


SI Table 3: List of parts screened for integration into miniaturized fluorescent detector, as well as those finally selected (dotted red box) for integration into the final device.

\begin{tabular}{|c|c|c|}
\hline Parts names & Parts numbers & Explanation \\
\hline \multirow[t]{4}{*}{ Photo detector } & 160-1909-1-ND, Digi-Key & Photo detector RED CLEAR 0603 SMD \\
\hline & 67-2219-1-ND. Digi-Key... & Photo detector. CLEAR 0603.SMD....... \\
\hline & 404-1211-1-ND, Digi-Key & Photo detector RED CLEAR SMD \\
\hline & 754-1930-1-ND, Digi-Key & Photo detector CLEAR 0603 SMD \\
\hline \multirow{3}{*}{$\begin{array}{l}\text { Emission filter } \\
\text { (Polarizing filter) }\end{array}$} & 10CGA-570, Newport Co. & $570 \mathrm{~nm}$ wavelength \\
\hline & 10CGA-590, Newport Co. & $590 \mathrm{~nm}$ wavelength \\
\hline & 10CGA-610 Newport Co. & 610nm.wavelength.......... \\
\hline \multirow[t]{5}{*}{ Light source } & P13497CT-ND, Digi-Key & LED GREEN 0603 SMD \\
\hline & 350-2044-1-ND, Digi-Key & LED GREEN CLEAR 0805 SMD \\
\hline & 350-1569-1-ND, Digi-Key. & LED GREEN 565NM 4SMD 1210 \\
\hline & 350-2053-1-ND.Digi-Key. & LED.GREEN CLEAR.1206.SMD.. \\
\hline & 492-1329-1-ND, Digi-Key & LED GREEN CLEAR 0805 SMD \\
\hline
\end{tabular}

